\title{
Predicting the discharge coefficient of oblique cylindrical weir using neural network techniques
}

\author{
Adnan A. Ismael ${ }^{1} \cdot$ Saleh J. Suleiman ${ }^{2} \cdot$ Raid Rafi Omar Al-Nima $^{2} \cdot$ Nadhir Al-Ansari $^{3}$ (i) \\ Received: 27 October 2020 / Accepted: 7 July 2021 / Published online: 4 August 2021 \\ (C) The Author(s) 2021
}

\begin{abstract}
Cylindrical weir shapes offer a steady-state overflow pattern, where the type of weirs can offer a simple design and provide the ease-to-pass floating debris. This study considers a coefficient of discharge $(\mathrm{Cd})$ prediction for oblique cylindrical weir using three diameters, the first is of $D_{1}=0.11 \mathrm{~m}$, the second is of $\mathrm{D}_{2}=0.09 \mathrm{~m}$, and the third is of $\mathrm{D} 3=0.06 .5 \mathrm{~m}$, and three inclination angles with respect to channel axis, the first is of $\theta_{1}=90$, the second is of $\theta_{2}=45$, and the third is of $\theta_{3}=30$. The Cd values for total of 56 experiments are estimated by using the radial basis function network (RBFN), in addition of comparing that with the back-propagation neural network (BPNN) and cascade-forward neural network (CFNN). Root mean square error (RMSE), mean square error (MSE), and correlation coefficient (CC) statics are used as metrics measurements. The RBFN attained superior performance comparing to the other neural networks of BPNN and CFNN. It is found that, for the training stage, the RBFN network benchmarked very small RMSE and MSE values of 1.35E-12 and 1.83E-24, respectively and for the testing stage, it also could benchmark very small RMSE and MSE values of 0.0082 and 6.80E-05, respectively.
\end{abstract}

Keywords Cylindrical weir · Neural network techniques $\cdot$ Discharge coefficient

\section{Introduction}

In hydro system projects, the discharge coefficient (Cd) of measuring the flow on weirs can be counted as one of the highest considerations for water controls. Many efforts have been made as a result of costly experiments to apply mathematical models for classifying the hydraulic specifications of oblique weirs. In

Responsible Editor: Broder J. Merkel

Nadhir Al-Ansari

nadhir.alansari@1tu.se

Adnan A. Ismael

adnan.ismael@ntu.edu.iq

Saleh J. Suleiman

salehjaafer@ntu.edu.iq

Raid Rafi Omar Al-Nima

raidrafi3@ntu.edu.iq

1 Technical Institute, Northern Technical University, Mosul, Iraq

2 Technical Eng. College, Northern Technical University, Mosul, Iraq

3 Department of Civil, Environmental and Natural Resources Engineering., Lulea University of Technology, Lulea 971 87, Lulea, Sweden the case of mathematical modelling, the soft computing methods are stated and computational fluid dynamics (CFD) techniques are used. For the CFD, turbulence models utilizing numerical analyses together with the Navier-Stokes calculations are solved by Yuce et al. (2015) and Gholami et al. (2014). A number of commercial softwares such as the Open source Field Operation and Manipulation (Open FOAM) have recently been provided for utilizing the CFD techniques. Exploiting the CFD for modelling the movement of an oblique cylindrical weir was reported by Yuce et al. (2015). It is notable that Yuce et al. (2015) have investigated the hydraulic characteristics of the weir of oblique cylindrical. It has been reported that utilizing the soft computing methods with the CFD modelling for expecting the discharge coefficient of oblique weirs. Cylindrical weirs have two characteristics of flow: firstly a stable pattern and secondly the simplicity in design. The floating debris can be ensured to be ease to pass especially when the channel width is limited. So, oblique weirs have an advantage of comparing with normal weirs when higher flood discharge is required to lowering the upstream head. Oblique weir increases the effective length of weir axes on the channel width which consequently increases the efficiency of weir. The $\mathrm{Cd}$ was predicted by Chelang et al. (2018) by using the adaptive neuro-fuzzy inference system (ANFIS) and multi-layer perceptron (MLP) techniques. Results 
Table 1 The experimental work details

\begin{tabular}{llllll}
\hline Group No. & Weir type & Series No. & Angle $(\theta)$ & Model diameter $(\mathrm{cm})$ & Run No. \\
\hline 1 & Traditional weir & $\mathbf{A}$ & $\mathbf{9 0}^{\circ}$ & 11 & $\mathbf{1 - 5}$ \\
& & & 9 & $\mathbf{6 - 1 0}$ \\
& & & 6.5 & $\mathbf{1 1 - 1 5}$ \\
2 & Oblique weir & $\mathbf{B}$ & $\mathbf{4 5}^{\circ}$ & 11 & $\mathbf{1 6 - 2 0}$ \\
& & & 9 & $\mathbf{2 1 - 2 5}$ \\
& & & 6.5 & $\mathbf{2 6 - 3 0}$ \\
$\mathbf{3}$ & $\mathbf{C}$ & $\mathbf{3 0}^{\circ}$ & 11 & $\mathbf{3 1 - 3 5}$ \\
& & & 9 & $\mathbf{3 6}-\mathbf{4 0}$ \\
& & & 6.5 & $\mathbf{4 1 - 4 5}$ \\
\hline
\end{tabular}

of running 143 labs were used for operation prediction. The results showed that the ANFIS technique modeled the discharge coefficient better than the MLP. Haghiabi et al. (2018) estimated the Cd of triangular labyrinth weir. The study presented 293 experiments, and the gamma test was conducted to gain the effective parameters of the $\mathrm{Cd}$. The accuracy of model is tested using the root mean square error (RMSE). The prior work of Azimfar et al. (2018) can be considered as a study example for pivot weirs discharge coefficient. They improved discharge coefficient for the flow conditions of submerge and free. Discharge coefficient is necessary in this area, because it is dimensionless. This makes employable in too many applications. The authors of this study concentrated on Bernoulli method and they utilized momentum equations. Better expectation accuracy for discharge coefficient of a rectangular weir with sharp edges was planned by Ebtehaj et al. (2018), where multi-objective machine learning (ML) techniques were exploited. They generalized a set of methods in the essential tools as the ANFIS was utilized and the system was supported by the genetic algorithm (GA) for denoting data handling and membership functions. Their system is being a multi-objective data expectation tool with the presence of one value decomposition. Some regression-based techniques and different single objective data expectation styles are also compared to the multi-objective system. Therefore, the study can be counted as a comprehensive literature. Nezami and Nekooie (2015) empirically investigated the discharge coefficient of trapezoidal side weir. They recognized in submerged flow a relationship for De-Marchi's coefficient. The performance of radial basis function networks (RBFNs), support vector machine (SVM), and multilayer perceptron networks were explored by Norouzi et al. (2019) for evaluating the labyrinth weirs discharge coefficient with quarter-round crests. The superior method has an understandable accuracy according to the simulation results. For instance, the correlation coefficient $\left(\mathrm{R}^{2}\right)$, mean absolute relative error (MARE), and RMSE values computed for the superior training method are 0.884, 0.0327, and 0.0156, respectively. Bonakdari et al. (2015) expected the triangular side weir discharge coefficient by utilizing the ANFIS.

Fig. 1 Flow chart of the testing programme

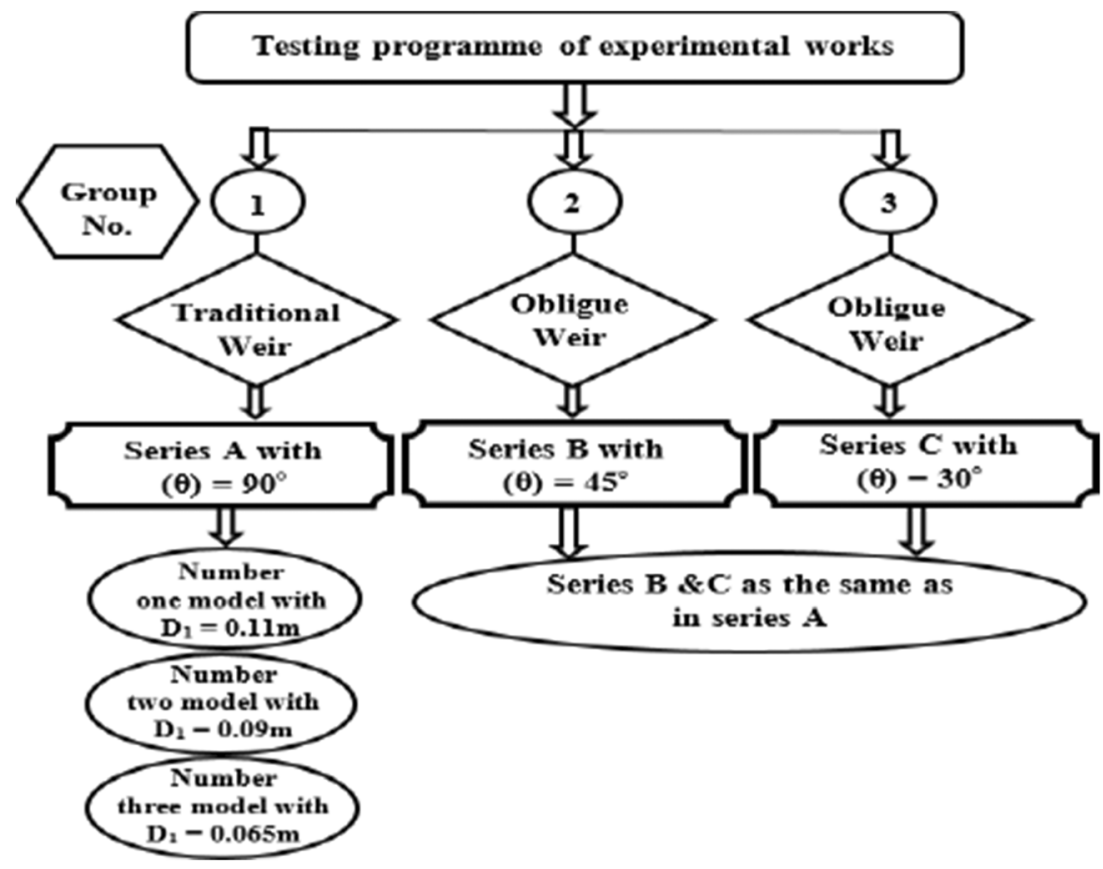


Fig. 2 Up view of the cylindrical oblique weir and open channel

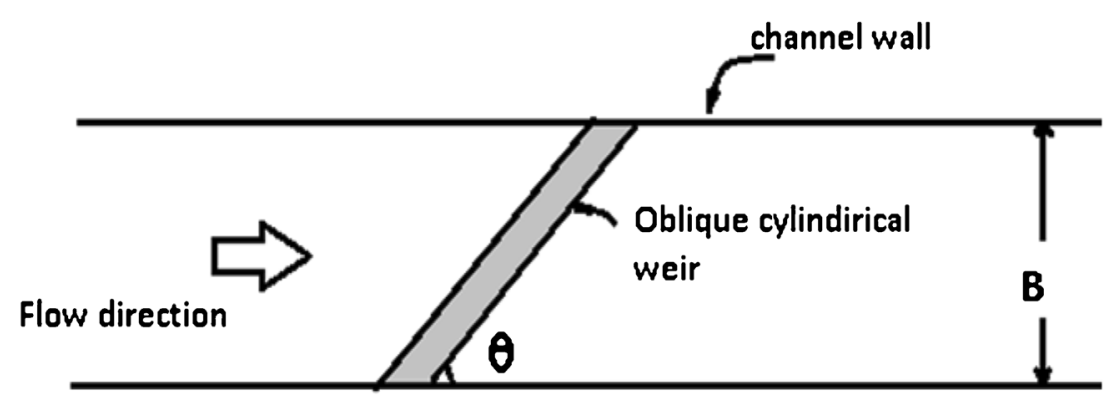

The aim of this investigation is to develop a suitable artificial neural network (ANN) model for predicting the $\mathrm{Cd}$ of oblique submerges cylindrical weir. The RBFN, BPNN, and CFNN models are adapted to accept five inputs of $\left(H_{w} / R\right.$, $\mathrm{L} / \mathrm{R}, \mathrm{H}_{\mathrm{w}} / \mathrm{D}, \mathrm{L} / \mathrm{H}_{\mathrm{w}}$, and $\left.\theta\right)$ and one output of $\left(\mathrm{C}_{\mathrm{d}}\right)$. As a result, the output values of $\mathrm{Cd}$ are intelligently predicted and this will lead to decrease the cost, efforts, and time of manually expecting the optimum values.

\section{Methodology}

The functional relationship for the discharge coefficient (or mathematically $\mathrm{C}_{\mathrm{d}}$ ) with the main flow parameters of normal and oblique cylindrical weirs can be expressed as follows. Yuce et al. (2015):

$$
\begin{aligned}
& f_{0}\left\{C_{d}, q, H_{w}, R, l, g, \rho, \mu, \theta\right\}=0 \\
& C_{d}=f_{1}\left\{\frac{H_{w}}{R}, \frac{L}{R}, \frac{H_{w}}{D}, \frac{L}{H_{w}}, \theta\right\}
\end{aligned}
$$

Where:

$C_{d}$ is the discharge coefficient,

$q \quad$ is the discharge over the weir per unit width $\left(\mathrm{m}^{3} / \mathrm{s} / \mathrm{m}\right)$,

$H_{w}$ is the energy head over the weir crest (m),

$R \quad$ is the radius of the weir crest (m),

$D$ is weir diameter (m),

$L \quad$ is the length of weir crest (m),

$H$ total head (m),

$d \quad$ is the water upstream depth, the circular weir under investigation ( $\mathrm{m}$ ) (in terms of vertical and oblique weirs)

$g \quad$ is the acceleration due to gravity $\left(\mathrm{m} / \mathrm{s}^{2}\right)$, $\mu \quad$ is the dynamic viscosity of water pa.s,

$\rho \quad$ is the mass density $\mathrm{Ns}^{2} / \mathrm{m}^{4}$ and

$\theta \quad$ is the angle of inclination of the weir with the channel wall.

\section{Experimental work}

For the purpose of studying the effect of oblique submerged cylindrical weirs on flow characteristics, three models made from the plastic were created, placed, and examined with various angles with channel wall. The models were divided into three groups depending on the angle of their oblique with the channel side $(\theta)$. The first group is traditional weir with $\theta=90$ , the second and third group are oblique weir with $\theta=45$ and 30 . Each one of these group contains one series. The first series is A, the second series is B, and the third series is C. Series $\mathrm{A}$ is divided into three models based on the diameter of the weirs (D): Number one model with $D_{1}=0.11 \mathrm{~m}$, number two model with $\mathrm{D}_{2}=0.09 \mathrm{~m}$, and number three model with $\mathrm{D}_{3}$ $=0.065 \mathrm{~m}$, also series $\mathrm{B}$ and $\mathrm{C}$ as the same as in series A, as shown in Table 1. Figure 1 flow chart of the testing programme and Fig. 2 the up view of the cylindrical weir method and open channel are represented, and they were used in this work. Figure 3 demonstrates the channel setup.

The value of cylindrical weir discharge coefficient is computed according to the following equation.

$$
\begin{aligned}
& q=C d^{*} \frac{2}{3} \sqrt{\frac{2 \mathrm{~g}}{3}} * H_{w}^{1.5} \\
& H_{w}=H-D \\
& H=d+q^{2} / 2 * g * d^{2}
\end{aligned}
$$

Fig. 3 The channel setup

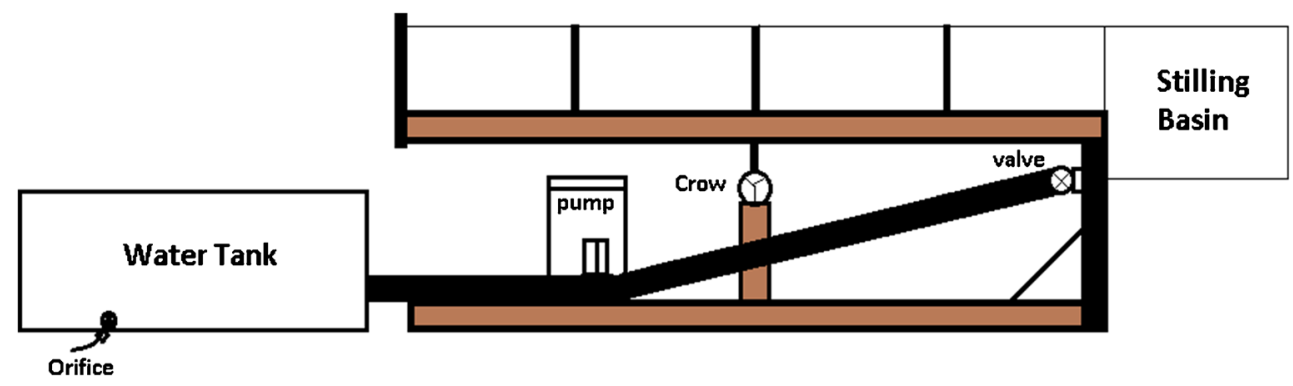


Fig. 4 The suggested RBFN structure. It consists of five inputs $\left(\mathrm{H}_{\mathrm{w}} / \mathrm{R}, \mathrm{L} / \mathrm{R}, \mathrm{H}_{\mathrm{w}} / \mathrm{D}, \mathrm{L} / \mathrm{H}_{\mathrm{w}}\right.$, and $\left.\theta\right)$ and one output $\left(\mathrm{C}_{\mathrm{d}}\right)$

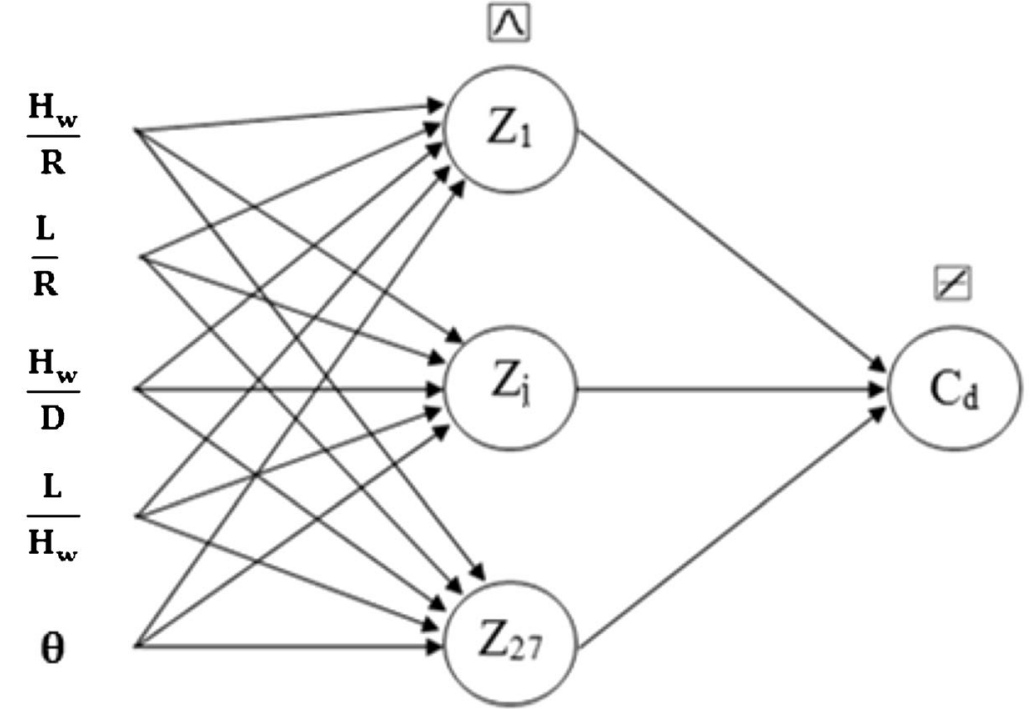

Input Layer
Hidden Layer

\section{Theoretical part}

In the case of establishing an intelligent method for predicting the $\mathrm{Cd}$ values, an efficient RBFN network is proposed. The RBFN is a type of artificial neural networks (ANNs). It consists of three main layers: input layer, hidden layer, and output layer. In the hidden layer, a radial basis function (RBF) is exploited, whereas, in the output layer, a linear function is used by Parsaie (2016). The suggested RBFN structure is given in Fig. 4 .

During the training stage, the RBFN generates the required weights by utilizing certain training data. These weights can be used later in the testing stage to evaluate new data that have not been given before.

The output values of the hidden layer are computed as in Eq. (6) Fausett (1994) and Kou et al. (2010). This equation is also known as the RBF:

$z_{j}=\exp \left[-\frac{\left\|\mathbf{x}-\mathbf{v}_{j}\right\|}{2 \sigma^{2}}\right], \quad j=1,2, \ldots, p$

Where $z_{i, j}$ is a hidden neuron's output, $\mathbf{x}$ is the input vector and $\mathbf{v}_{\mathrm{j}}$ is the vector of weights between the input and hidden layers, $\sigma$ is a smoothing parameter for the Gaussian distribution function, and $p$ is the number of hidden neurons.

$$
y=\sum_{j=1}^{p} z_{j} w_{j}
$$

Where $y$ is the outcome of the single output neuron and $w_{j}$ is the connected weights between the hidden and output layers.

The RBFN has many training advantages over other neural networks. These advantages can be highlighted as follows:

- Its training is so fast as it spends a very short time during the training stage, Kisi and Ay (2012). On the other hand, many other neural networks require long training times during the training stage.

- It needs only one iteration to fully accomplish the training stage, Kisi and Ay (2012). Whilst, some other neural networks (such as the back propagation, Cascade-forward, and Bayesian) are iterated until reaching their goal.

- It does not deceive by the local minima problem Kisi and Ay (2012) as other neural networks (such as the back propagation).

- It can easily remove or add training data because of its RBF facility as mentioned in Al-Nima (2017) and AlNima et al. (2017a). Whereas, other networks may require repeating the training stage.
Table 2 Comparison table between our employed RBFN and other networks (the CFNN and BRNN)

\begin{tabular}{llll}
\hline Neural network type & Number of trained epochs & Mean square error of train & Mean square error of test \\
\hline RBFN & $\mathbf{1}$ & $\mathbf{1 . 8 3 E}-\mathbf{2 4}$ & $\mathbf{6 . 8 0 E - 0 5}$ \\
CFNN & 59 & $3.45 \mathrm{E}-07$ & $7.79 \mathrm{E}-05$ \\
BPNN & 306 & $5.26 \mathrm{E}-08$ & 0.0002 \\
\hline
\end{tabular}




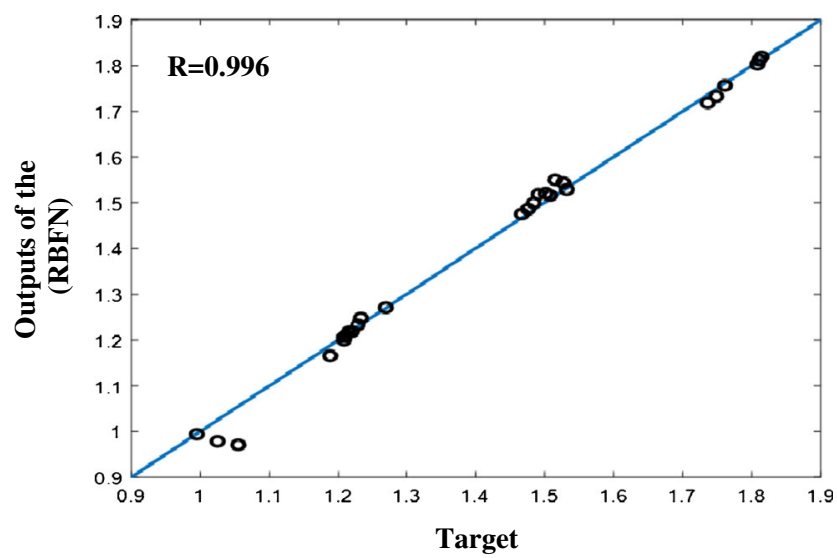

Fig. 5 The regressing relationship between the testing outputs of the RBFN and its desired target

- This network is effective as evidenced in Al-Nima et al. (2018) and Al-Nima (2012).

The suggested RBFN network is compared with other ANN networks. These are the CFNN and BRNN. These networks can effectively be adapted and utilized as in Al-Nima et al. (2019a) and Raid Al-Nima (2013).

- The most common statistical computation methods for evaluating the regression of proposed model are the MSE and RMSE. Minimum statistical values can refer to the best model. The RMSE and MSE can be computed as in the following equations:

$$
\begin{aligned}
& \text { RMSE }=\sqrt{\frac{1}{N}} \sum_{i=1}^{N}\left(C_{i, \text { Observed }}-C_{i, \text { eseimated }}\right)^{2} \\
& \text { MSE }=\frac{1}{N} \sum_{i=1}^{\mathrm{N}}\left(C_{i} \text {, observed }-C_{i} \text {, eseimated }\right)^{2} \\
& \mathrm{R}^{2}=\frac{\left(\sum_{t=1}^{\mathrm{N}}\left(\mathrm{A}_{\mathrm{t}}-\mathrm{A}_{\text {mean }}\right)\left(\mathrm{E}_{\mathrm{t}}-\mathrm{E}_{\text {maen }}\right)^{2}\right.}{\sum_{\mathrm{t}=1}^{\mathrm{n}}\left(\mathrm{A}_{\mathrm{t}}-\mathrm{A}_{\text {mean }}\right)^{2} \sum_{\mathrm{t}=1}^{\mathrm{n}}\left(\mathrm{E}_{\mathrm{t}}-\mathrm{E}_{\text {mean }}\right)^{2}}
\end{aligned}
$$

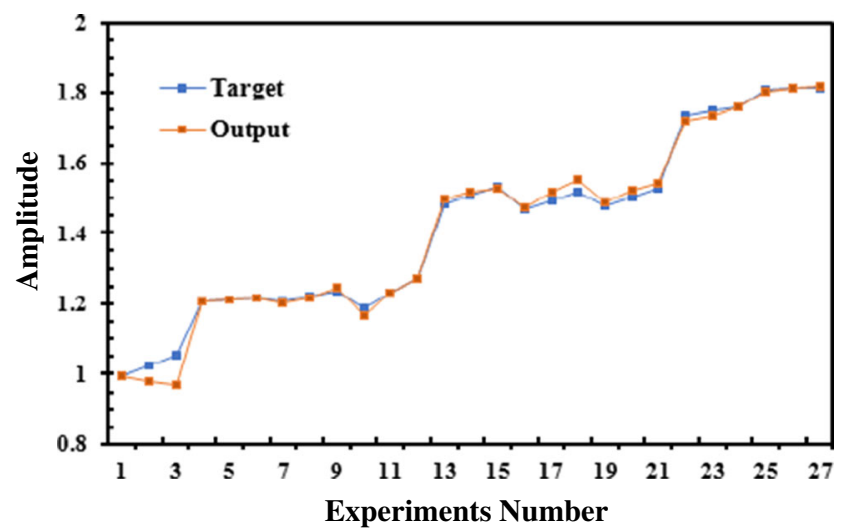

Fig. 6 Testing relationship between the RBFN output values and the desired target values
Where:
$\mathrm{N}$

$\mathrm{A}_{\mathrm{t}}$

$\mathrm{E}_{\text {mean }}$ and $\mathrm{A}$

mean is the number of data set, $\left(\mathrm{C}_{\mathrm{i}}\right)$ is the discharge coefficient.

is the observed value from experimental work and $E_{t}$ is the evaluated or estimated value, and are the series mean value which are the estimated and observed.
These statistical computation methods are used in this study as they can give a good idea for evaluating the ANN models.

\section{Result and discussion}

The acquired data from experimental work has been prepared for the ANN techniques. Furthermore, the dataset was partitioned into two groups: a group of training and a group of testing.

The proposed RBFN has been established and implemented. It has attained superior performance comparing to other neural networks (BPNN and CFNN). The employed inputs to the RBFN are $\mathrm{H}_{\mathrm{w}} / \mathrm{R}, \mathrm{L} / \mathrm{R}, \mathrm{H}_{\mathrm{w}} / \mathrm{D}, \mathrm{L} / \mathrm{H}_{\mathrm{w}}$, and $\theta$. On the other hand, the employed output to the RBFN is $\mathrm{C}_{\mathrm{d}}$. Table $2 \mathrm{dem}$ onstrates comparison results between the different neural networks.

From Table 2, it can be seen that the BPNN obtained a mean square error of 0.0002 for the training stage after 306 epochs. So, it spent very long time during the train. Regarding the testing stage, it obtained a means square error of 5.26E-08 and this can be considered as a moderate error testing value. This is expected as the BPNN is an old fashion of neural network and it has many drawbacks such as spending very long training time and its results are not so satisfied.

CFNN attained similar mean square error of 3.45E-07 for the training stage after 59 epochs. For the testing stage, it attained a mean square error of $7.79 \mathrm{E}-05$ and this is the highest error testing value. This network has additional connections between the input and output layers. Therefore, it can spend moderate training time. However, its training and testing performances are still not satisfied.

\begin{tabular}{|c|c|c|c|c|c|c|}
\hline \multirow[t]{2}{*}{ Method } & \multicolumn{3}{|c|}{ Train data set } & \multicolumn{3}{|c|}{ Test data set } \\
\hline & MSE & RMSE & $R^{2}$ & MSE & RMSE & $R^{2}$ \\
\hline RBFN & $1.83 \mathrm{E}-24$ & $1.35 \mathrm{E}-12$ & 0.999 & $6.80 \mathrm{E}-05$ & 0.0082 & 0.993 \\
\hline BRNN & $5.26 \mathrm{E}-08$ & 0.00023 & 0.997 & 0.0002 & 0.014 & 0.992 \\
\hline CFNN & $3.45 \mathrm{E}-07$ & 0.0006 & 0.997 & 7.79E-05 & 0.009 & 0.991 \\
\hline
\end{tabular}

Table 3 The RMSE, MSE, and $\mathrm{R}^{2}$ of each model in the training and testing stages 

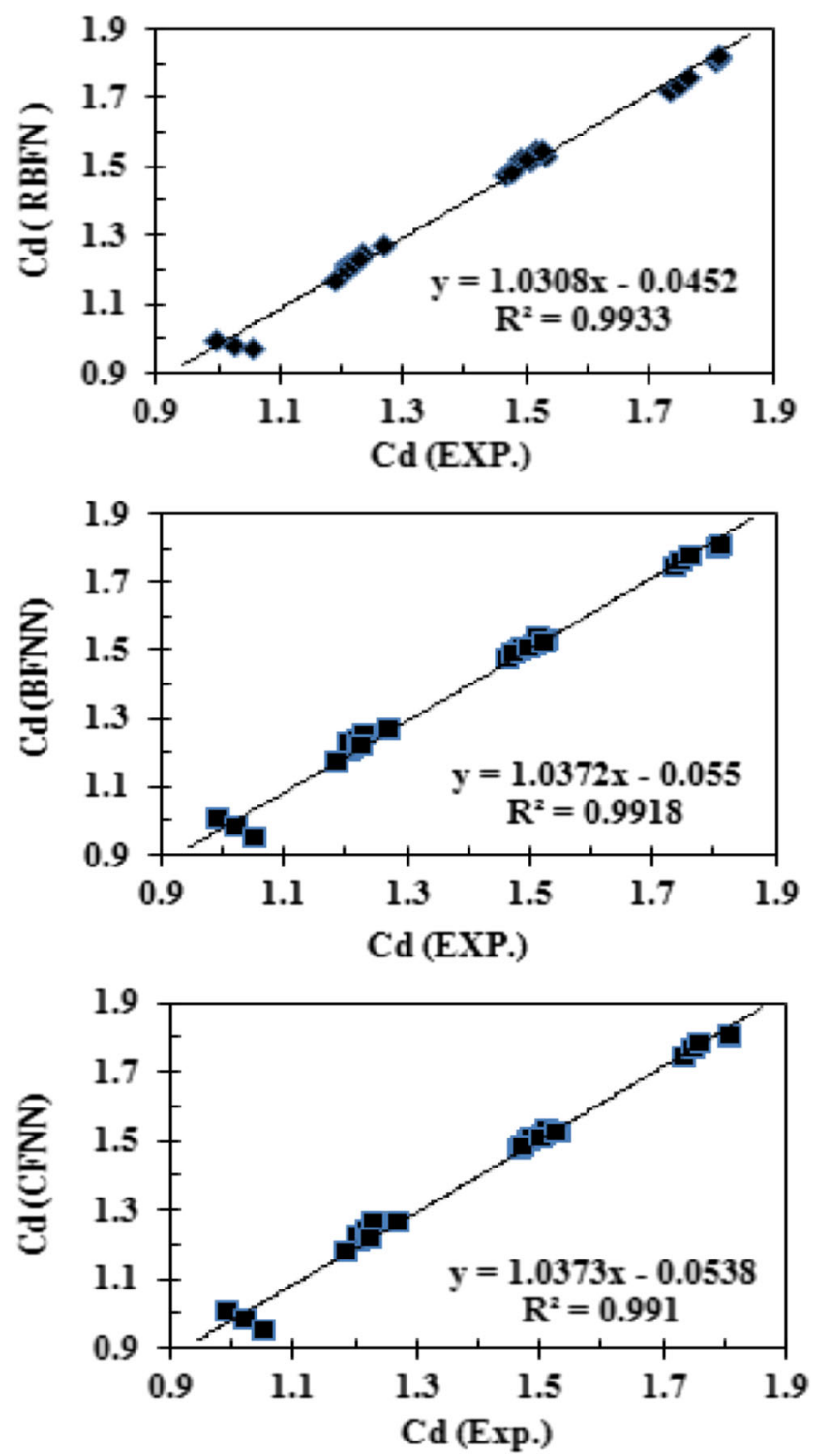

Fig. 7 Performance of model RBFN, BFNN, and CFNN during test period

Obviously, the RBFN network benchmarked a smallest mean square error of $1.83 \mathrm{E}-24$ for the training stage after only one epoch. Therefore, it is faster than all other compared neural networks. It also could benchmark the smallest testing error value of $6.80 \mathrm{E}-05$

Figure 5 provides the regressing relationship between the testing output of the RBFN and its desired target.

Clearly, Fig. 5 shows a successful relationship between the desired testing target and the actual output of RBFN. The recorded regression value here is $R=0.996$. This value is another evidence about the successfulness of our RBFN as it is so close from the optimal value $R=$ 1. Figure 6 demonstrates another testing relationship between the desired target values and the RBFN output values.

From this figure, it can be observed that a very close relationship is shown between the desired target values and the RBFN output values. This is because that the curve of the output values is corresponding to the curve of the desired target values. Figures 7 and 8 show performances of training and testing stages, where scatter plots are depicts. The RMSE, MSE, and $\mathrm{R}^{2}$ of each model in the training and testing stages are given in Table 3.

It can be yield that the RBFN model attained the best results of predicting the Cd compared to other networks. It can be signified as one of other approaches as in Al-Nima et al.
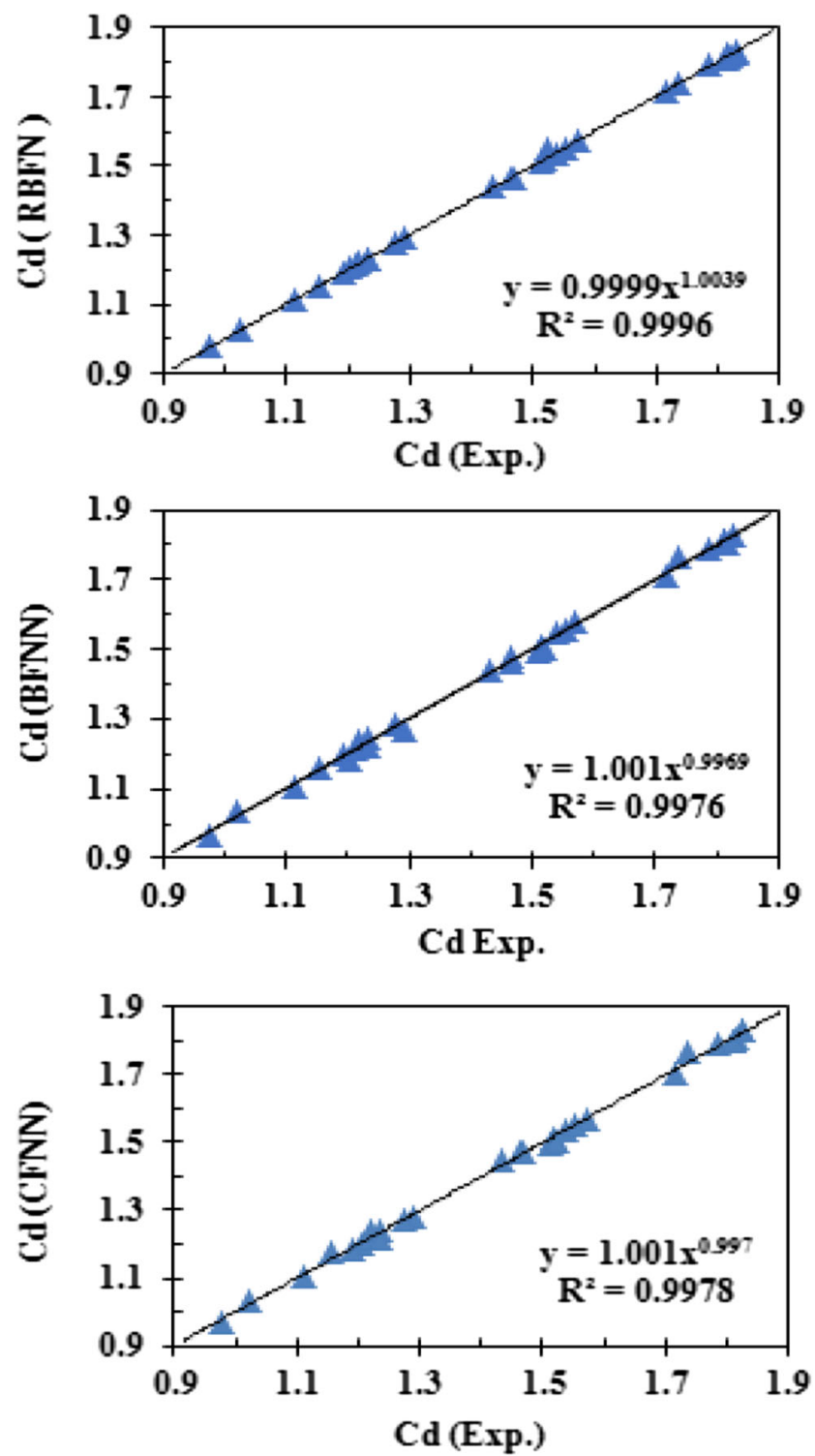

Fig. 8 Performance of model RBFN, BFNN, and CFNN during training period 
(2014), (2017b), (2020b), Abdullah et al. (2017), Al-Nima (2010), Al-Kaltakchi et al. (2018), Al-Nima et al. (2019b, 2019c), Khalil et al. (2009), Al-Nima and Kasim (2008), AlNima et al. (2020a), Al-Ridha et al. (2019), and Al-Nima et al. (2019b).

\section{Conclusion}

In this paper, three theoretical models were improved. These are the RBFN, CFNN, and BRNN. To specify discharge coefficient for cylindrical weir with various angle of inclinations and various diameters, 56 experimental data series with combinations of different inputs were exploited. Estimating $\mathrm{Cd}$ values of the oblique cylindrical weirs is considered in this paper. Experiment dataset was utilized with different ANN techniques. The performance of the RBFN model was compared with the CFNN and BRNN. The comparison results indicated that the RBFN model performs better than the other models. The RBFN network benchmarked a smallest mean square error of 1.83E-24 for the training stage after only one epoch. Therefore, it is faster than all other compared neural networks. It also could benchmark the smallest testing error value of $6.80 \mathrm{E}-05$.That is, the RBFN model reduced the RMSE in testing stage by $9 \%$ and $41 \%$ for the CFNN and BRNN, respectively.

Funding Open access funding provided by Lulea University of Technology.

\section{Declarations}

Conflict of interest The authors declare that they have no competing interests.

Open Access This article is licensed under a Creative Commons Attribution 4.0 International License, which permits use, sharing, adaptation, distribution and reproduction in any medium or format, as long as you give appropriate credit to the original author(s) and the source, provide a link to the Creative Commons licence, and indicate if changes were made. The images or other third party material in this article are included in the article's Creative Commons licence, unless indicated otherwise in a credit line to the material. If material is not included in the article's Creative Commons licence and your intended use is not permitted by statutory regulation or exceeds the permitted use, you will need to obtain permission directly from the copyright holder. To view a copy of this licence, visit http://creativecommons.org/licenses/by/4.0/.

\section{References}

Abdullah MAM, Al-Nima RR, Dlay SS, Woo WL and Chambers JA, (2017)“Cross-spectral iris matching for surveillance applications”,
Springer, Surveillance in Action Technologies for Civilian, Military and Cyber Surveillance, Chapter 5.

Al-Kaltakchi MT, Omar RR, Abdullah HN, Han T, Chambers JA (2018) Finger texture verification systems based on multiple spectrum lighting sensors with four fusion levels. Iraq J Inform Commun Technol 1(3):1-16

Al-Nima RR, (2010)"Design a biometric identification system based on the fusion of hand geometry and backhand patterns", Iraq J Stat Sci

Al-Nima RR (2012) Human authentication with earprint for secure telephone system. Iraq J Comp Commun Control Syst Eng IJCCCE 12(2):47-55

Al-Nima RRO, (2013) "Steganography for text in video file using radial neural network", 3rd International Scientific Conference, Foundation of Technical Education, Technical Education, Najaf.

Al-Nima RR, (2017) "Signal processing and machine learning techniques for human verification based on finger textures, $\mathrm{PhD}$ thesis, School of Engineering", Newcastle University, UK

Al-Nima RR, Kasim S (2008) Picture recognition by using linear associative memory neural network. Tikrit J Pure Sci 13(3):266-273

Al-Nima RR), Dlay S and Woo W, (2014) "A new approach to predicting physical biometrics from behavioural biometrics", Int J Comp Inform Syst Control Eng. 8(11)

Al-Nima RRO, Abdullah MAM, Al-Kaltakchi MTS, Dlay SS, Woo WL, and Chambers JA, (2017a)"Finger texture biometric verification exploiting a Multi-scale Sobel Angles local binary pattern and score-based fusion", Elsevier, Digital Signal Processing 70

Al-Nima RRO, Dlay SS, Woo WL and Chambers JA, (2017b)“Efficient finger segmentation robust to hand alignment in imaging with application to human verification", 5th IEEE International Workshop on Biometrics and Forensics (IWBF), .

Al-Nima RRO, Al-Kaltakchi M, Al-Sumaidaee S, Dlay S, Woo W, Han T and Chambers J, (2018)"Personal verification based on multi-spectral finger texture lighting images", IET Signal Processing, 12(9)

Al-Nima RRO, Al-Obaidy NA and Al-Hbeti LA, (2019a) "Segmenting finger inner surface for the purpose of human recognition", 2nd International Conference on Engineering Technology and its Applications (IICETA), IEEE, pp. 105-110.

Al-Nima RRO, Al-Ridha MY, Abdulraheem FH (2019b) Regenerating face images from multi-spectral palm images using multiple fusion methods. Telkomnika 17(6):3120-3129

Al-Nima RRO, Abdulraheem FH, Al-Ridha MY (2019c) Using handdorsal images to reproduce face images by applying back propagation and cascade-forward neural networks. In: $2^{\text {nd }}$ International Conference on Electrical, Communication, Computer, Power and Control Engineering (ICECCPCE19). IEEE, Mosul, pp 13-14

Al-Nima RRO, Han T, Chen T, Dlay S and Chambers J, (2020a) "Finger texture biometric characteristic: a survey", arXiv preprint arXiv:2006.04193.

Al-Nima RRO, Han T, Chen T (2020b) Road tracking using deep reinforcement learning for self-driving car applications. In: Burduk R, Kurzynski M, Wozniak M (eds) Progress in Computer Recognition Systems, CORES 2019, Advances in Intelligent Systems and Computing, 977th edn. Springer, Cham

Al-Ridha MY, Al-Nima RRO, Anaz AS (2019) Adaptive neuro-fuzzy inference system for controlling a steam valve. in 2019 IEEE 9th International Conference on System Engineering and Technology (ICSET), Shah Alam

Azimfar SM, Hosseini SA, Khosrojerrdi A (2018) Derivation of discharge coefficient of a pivot weir under free and submergence flow conditions. Flow Meas Instrum 59:45-51. https://doi.org/10.1016/j. flowmeasinst.2017.11.010 
Bonakdari H, Zaji AH, Shamshirband S, Hashim R, Petkovic D (2015) Sensitivity analysis of the discharge coefficient of a modified triangular side weir by adaptive neuro-fuzzy methodology. Measure 73:74-81

Chelang A, Abdul-Karim A, Ismael A (2018) Prediction of discharge coefficient for cylindrical weirs using adaptive Neuro fuzzy inference system ANFIS and multilayer neural networks MLP. Int J Appl Eng Res ISSN 0973-4562 13(9):7042-7051

Ebtehaj I, Bonakdari H, Gharabaghi B (2018) Development of more accurate discharge coefficient prediction equations for rectangular side weirs using adaptive neuro-fuzzy inference system and generalized group method of data handling. Measurement 116(018):473482. https://doi.org/10.1016/j.measurement.2017.11.023

Fausett LV (1994) Fundamentals of neural networks: architectures, algorithms, and applications. Prentice Hall Inc., Upper Saddle River

Gholami A, Akhtari M, Bonakdari H, Javadi A (2014) Experimental and numerical study on velocity fields and water surface profile in a strongly-curved $90^{\circ}$ open channel bend. Eng Appl Comp Fluid Mech 8(3):447-461

Haghiabi AH, Parsaie A, Ememgholizadeh S (2018) Prediction of discharge coefficient of triangular labyrinth weirs using adaptive Neuro fuzzy inference system. Alexandria Eng J 57:1773-1782
Khalil MR, Majeed MS, and Omar RR, (2009) "Personal identification with iris patterns", AL-Rafidain J Comp Sci Math Coll Comp Sci Math/Univ Mosul/Iraq, 6(1).

Kisi O, Ay M (2012) Comparison of ANN and ANFIS techniques in modeling dissolved oxygen. In Proceedings of the Sixteenth International Water Technology Conference (IWTC 16), Istanbul, Turkey

Kou J, Xiong S, Wan S, and Liu H, (2010)“The incremental probabilistic neural network", in 6th International Conference on Natural Computation (ICNC) 3

Nezami F, Nekooie M (2015) Discharge coefficient for trapezoidal weir. Alexandria Eng J 54(3):595-605

Norouzi R, Daneshfaraz R, Ghaderi A (2019) Investigation of discharge coefficient of trapezoidal labyrinth weirs using artificial neural networks and support vector mechines. Applied Water Science 9(7): 148

Parsaie A (2016) Predictive modelling the side weir discharge coefficient using neural network. Model Earth Syst Environ 2(2):63

Yuce M, Al-Babely A, Al-Dabbagh M (2015) Flow simulation over oblique cylindrical weirs. Can J Civ Eng 42:389-407 